\title{
Effect of Culture Medium Incorporated with Ocimum sanctum Extract in Enhancing Anti-MRSA activity of Endophytic Fungus, Lasiodiplodia pseudotheobromae
}

\author{
Mohd Taufiq Mat Jalil ${ }^{1 *}$ (D), Nurul Aili Zakaria1 ${ }^{10}$ and Darah Ibrahim² \\ ${ }^{1}$ School of Biology, Faculty of Applied Sciences, Universiti Teknologi MARA, 40450, Shah Alam, Selangor, \\ Malaysia. \\ ${ }^{2}$ Industrial Biotechnology Research Laboratory, School of Biological Sciences, Universiti Sains Malaysia, 11800 \\ Minden, Penang, Malaysia.
}

\begin{abstract}
The effect of incorporating plant extract in the culture medium on anti-MRSA activity of Lasiodiplodia pseudotheobromae IBRL OS-64, was investigated in the present study. On disk diffusion assay, the ethyl acetate fungal extract from culture medium supplemented with host plant extract (HPE) of Ocimum sanctum leaves demonstrated good anti-MRSA activity with a diameter inhibition zone of $22.6 \pm 0.6$ $\mathrm{mm}$. Meanwhile, the minimal inhibition concentration (MIC) values of the extract from YES broth and YES broth incorporated with HPE were $1000 \mu \mathrm{g} / \mathrm{mL}$ and $250 \mu \mathrm{g} / \mathrm{mL}$, respectively. The MBC values were $8000 \mu \mathrm{g} / \mathrm{mL}$ and $500 \mu \mathrm{g} / \mathrm{mL}$, respectively. The YES + HPE extracts exerted bactericidal effect against the test bacteria since the MBC/MIC ratio was less than or equal to 4 . The time-kill study revealed a $90 \%$ of growth reduction of MRSA ATCC 33591 after $16 \mathrm{~h}$ exposure to the fungal extract cultured in YES + HPE. Ironically, for fungal extract grown in YES broth, time-kill curve showed a regrowth pattern of bacterial cells after $24 \mathrm{~h}$ exposed to the extract. Therefore, the present study suggested that the addition of HPE in the culture medium could enhance the anti-MRSA activity of endophytic fungus, $L$. pseudotheobromae IBRL OS-64 against MRSA ATCC 33591.
\end{abstract}

Keywords: Anti-MRSA activity, Lasiodiplodia pseudotheobromae, Ocimum sanctum, Minimal Inhibition Concentration (MIC), Minimal Bactericidal Concentration (MBC), Time-kill study

*Correspondence: taufiqjalil@uitm.edu.my; +6013 4158746

(Received: June 04, 2021; accepted: July 02, 2021)

Citation: Jali MTM, Zakaria NA, Ibrahim D. Effect of Culture Medium Incorporated with Ocimum sanctum Extract in Enhancing Anti-MRSA activity of Endophytic Fungus, Lasiodiplodia pseudotheobromae. J Pure Appl Microbiol. 2021;15(3):1398-1408. doi: 10.22207/JPAM.15.3.32

(C) The Author(s) 2021. Open Access. This article is distributed under the terms of the Creative Commons Attribution 4.0 International License which permits unrestricted use, sharing, distribution, and reproduction in any medium, provided you give appropriate credit to the original author(s) and the source, provide a link to the Creative Commons license, and indicate if changes were made. 


\section{INTRODUCTION}

The search of a new antibiotic agent is a need due to the emergence of multidrug resistant strains. Staphylococcus aureus is one of Gramnegative bacteria that demonstrated antimicrobial resistance which is a major global health concern and the strain could cause a wide range of infections including soft tissue, bone, joints, skin and infections associated with prosthetic devices and indwelling catheters ${ }^{1}$. MRSA is a strain that has been initially described in 1960 s can cause potentially fatal diseases such as endocarditis, severe sepsis, pneumonia and toxinoses including toxic shock syndrome ${ }^{2}$. Persistent bacteremia caused by MRSA is a significant cause of mortality and morbidity ${ }^{3}$.

Due to emergence of multi drug resistant strains, the search of new potential antimicrobial source is a need. To date, the discovery of bioactive substances is mainly focused on microorganisms of soil origin. However, Guo et $\mathrm{al}^{4}$ reported there are rapid decrease in the discovery for new sources of microbial secondary metabolite with new pharmaceutical properties. Nowadays, endophytes have been used as alternative source for bioactive compound production due to their potential benefits. Endophytes can be defined as microorganism that resided in the plant cells without cause any negative effects to their host ${ }^{5}$. According to Strobel and Daisy ${ }^{6}$, the abundance of endophytes with more than one million species that occupy a unique biotope made them a great choice in study of natural products and subsequently avoids replication in research. Zhang et $\mathrm{al}^{7}$ stated that endophytic fungi could produce a large number of bioactive compounds as compared to other microorganisms. Besides that, fungal endophytes can produce bioactive substances mimicking their host such as production of taxol by Taxomyces andreanae ${ }^{8}$. Many previous studies reported the potential of endophytic fungi as a source of natural antibiotic drugs. For instance, Hussain et al ${ }^{9}$ reported the potential of endophytic fungus identified as Phoma sp. that has been isolated from Fucus serratus as antimicrobial drug. Their study revealed that three compounds had successfully isolated from fungal extract such as emodin, (3R)-5-hydroxymellein and phomalacton exhibited a good antimicrobial activity against several bacteria including Bacillus megaterium.
Lasiodiplodia pseudotheobromae is a well-known plant pathogen from family Botryosphaeriaceae that frequently infected grapevine, persimmon, woody plants and mango. It can cause several symptoms to the infected plant including cluster/fruit dropping ${ }^{10}$, cankers ${ }^{11}$, pedicel/peduncle discoloration ${ }^{12}$, fruit rot $^{13}$ and dieback ${ }^{14}$. This strain was reported to possess several biological activities including proteolytic, fibrinolytic ${ }^{15}$, cytotoxic ${ }^{16}$ and antibacterial ${ }^{17}$ activities. However, the information regarding on bioactive compounds and biological activities of L. pseudotheobromae is very scarce.

The production of antimicrobial substances by endophytes can be enhanced by optimization of fermentation conditions, gene modifications, enzymes inductions and mixed culture fermentation ${ }^{18}$. Mutualistic and symbiotic relationships between plantassociated endophytes offers several benefits and advantages to their host plant and vice-versa. Fungal endophytes can prevent their host from desiccation, helping greater access to nutrients, formulating hormone such as auxin, inhibiting plant pathogenic fungi and preventing from harsh environments ${ }^{19 ; 20}$. In return, their hosts provide them with space, shelter, and also growth nutrients. Episymbiotic fungi modify their host plant tissue due to nutrients acquirement and epidermal cell of the host leaf that is lacking of waxy cuticle and hypertrophied in order to prevent escape of nutrient and water ${ }^{21}$. In cultivation of endophytic fungi, the culture supplemented with HPE able to increase their antimicrobial potential since the addition of host plant provided growth substances and needed nutrients to biosynthesize the cellular components and hence induce the production of secondary metabolites ${ }^{22}$. Similarly, Gogoi et $\mathrm{al}^{23}$ also postulated the supplement of host plant water extract into culture medium is crucial to enhance production of secondary metabolite production by fungal endophytes. Hence, the present study aimes to examine the effect of HPE incorporated in culture medium in enhancing anti-MRSA activity of an endophytic fungus isolated from medicinal plant.

\section{MATERIALS AND METHODS \\ Microbial cultures}

The fungal culture, Lasiodiplodia 
pseudotheobromae IBRL OS-64 was deposited at the IBRL, School of Biological Sciences, Universiti Sains Malaysia, Penang, Malaysia. The fungal culture was grown on potato dextrose agar supplemented with fine powdered host plant $(2 \mathrm{~g} / \mathrm{L})$. The test bacterium, MRSA ATCC 33591 culture (from clinical source) was grown on blood agar (BA) and inversely incubated for 24 hours at $37^{\circ} \mathrm{C}$. Microbial cultures were then kept in a chiller at $4^{\circ} \mathrm{C}$ due to further use.

\section{Preparation of bacterial suspension}

The suspension was performed by taking single colonies from 24 -h-old bacterial culture and introduced them into $5 \mathrm{~mL}$ sterile saline $(0.85 \%, \mathrm{w} / \mathrm{v})$. The turbidity was adjusted using 0.5 McFarland standards to obtain approximately $1 \times$ $10^{8} \mathrm{CFU} / \mathrm{mL}$ of the bacterial suspension.

\section{Preparation of host plant extract}

Host plant extract was prepared by boiling $5 \mathrm{~g}$ of host plant powder in $1000 \mathrm{~mL}$ distilled water for $30 \mathrm{~min}$. Prior to that, Ocimum sanctum leaves were dried under sunlight until constant weight achieved. The dried leaves were ground using a dry mill blender (Panasonic, Dry Mill MX-EX1081) to obtain fine leaf powder.

Culture medium, fermentation, and extraction

Yeast extract sucrose (YES) broth was done by employing procedures described by Taufiq and Darah ${ }^{24}$. Two types of YES broth used in the present study, YES broth incorporated with host plant extract and YES broth. The fermentation and extraction process were employed methods described by Taufiq and Darah ${ }^{17}$.

\section{Disk diffusion assay}

Antibacterial activity of the endophytic fungal extracts was determined following the method described by $\mathrm{CLSI}^{25}$. Five percent of ethyl acetate and $30 \mu \mathrm{g} / \mathrm{mL}$ of chloramphenicol were used as negative and positive controls, respectively. Formation of inhibition zone surrounding the disc was observed and measured. The experiments were performed in triplicates.

Determination of Minimal Inhibitory Concentration (MIC) and Minimal Bactericidal Concentration $(\mathrm{MBC})$ values

The MIC and MBC values of the extract were determined following the method described by $\mathrm{CLSI}^{26}$ in a sterile U-shaped microtiter plate. A $\mathrm{p}$-iodonitrotetrazolium violet (INT) solution was used as a growth indicator. MIC value of the extract was the lowest dilution of the extract showing no bacterial growth (indicating by INT color). Meanwhile, the lowest concentration of the MIC well with no visible of bacterial growth on MHA was recorded as the MBC value of the extract.

\section{Time-kill study}

The time-kill study was employed to determine the efficacy of the fungal extracts towards test bacterium according to methods described by Taufiq and Darah ${ }^{24}$. Four types of treatments used in the study viz. Chloramphenicol $(30 \mu \mathrm{g} / \mathrm{mL}), \mathrm{YES}+\mathrm{HPE}$ extract $(250 \mu \mathrm{g} / \mathrm{mL})$, YES extract $(1000 \mu \mathrm{g} / \mathrm{mL})$, and control. A time-kill graph ( $\log _{10} \mathrm{CFU} / \mathrm{mL}$ vs. time) was constructed for each fungal extract concentrations and control. At the meantime, the time needed to eliminate the growth of bacterial cells at 50\%, $90 \% 99 \%$ and 99.9\% was determined.

\section{Thin layer chromatography (TLC)}

TLC was purposely done to separate the bioactive fungal crude extract by following method described by Kagan and Flythe ${ }^{27}$. The square pieces of $2 \mathrm{~cm} \times 11 \mathrm{~cm}$ aluminium- backed thin layer chromatography (TLC) plates were cut accordingly using a sharp penknife. Following that, the plates were lightly drawn using a pencil to horizontally mark the baseline of the spots at a distance of $1.0 \mathrm{~cm}$ of the lower edge of the TLC plate. An aliquot of the ethyl acetate partitioned extract that has been re-dissolved with methanol was dipped using a capillary glass tube and then spotted on the middle point of the horizontal line of the silica plate. The silica plate with the spots was allowed to dry in a moving air stream and the solvents were allowed to run until it reaches 0.5 $\mathrm{cm}$ from the top of TLC plate.

\section{Contact agar diffusion bioautography assay}

Contact agar diffusion bioautography was performed by employing method described by Dewanjee et $a^{28}$. The TLC plate that was previously developed was placed on the surface of the Mueller-Hinton agar (MHA) and left overnight in a fridge at $4^{\circ} \mathrm{C}$ to allow the diffusion of developed compound to the agar. The plate was then inoculated with test bacteria after removing the TLC chromatogram on the agar surface. The final concentration of the bacterial inoculum was set to $5 \times 10^{5} \mathrm{CFU} / \mathrm{mL}$ with the volume of MHA was $20 \mathrm{~mL}$ per plate. The agar plates were then incubated in an inverted condition for 24 hours at 
$37^{\circ} \mathrm{C}$. The bacterial growth inhibition appeared as clear zones around the active spot was observed and recorded. To conduct phytochemical analysis, the previously developed TLC plate was fumigated with iodine crystals vapour in a closed container and the brown spot indicates the presence of lactone ${ }^{29}$. On the other hand, another newly developed TLC plate was sprayed 1\% aqueous ferric chloride $\left(\mathrm{FeCl}_{3}\right)$. Appearance of green, black, blue and purple colours indicated the presence of phenol $^{30}$.

\section{Statistical analysis}

The experimental data were recorded in triplicates and analysed by means of the One-way ANOVA using SPSS 15.0. Duncan's test was used to access the differences between means. If $p$ value less than 0.05 , the results were considered statistically significant.

\section{RESULTS AND DISCUSSION}

Disk diffusion has been the main procedures for antimicrobial susceptibility testing in the microbiological laboratories since Bauer Kirby first discovered the methods in the $1960 \mathrm{~s}^{31}$. According to Coorevits et $\mathrm{al}^{32}$, this method has many advantages including the possibility of executing direct susceptibility testing, flexible, cheap, and allows the visibility of growth, mixed cultures, and correct inoculum. However, the depth of culture medium and the diffusion rate of the extract could affect the susceptibility towards test microorganisms ${ }^{33}$. This assay was employed in the present study to access anti-MRSA activity of fungal extracts from fermentative broth and fungal biomass that fermented in YES broth and YES broth + HPE. The study was carried out to prove the addition of HPE in culture medium could increase the production of bioactive substances with anti-MRSA activity by endophytic fungus since
Taufiq and Darah ${ }^{24}$ reported that the improvement of cultural conditions such as the addition of the HPE in culture media could enhance anti-MRSA activity.

Table 1 shows anti-MRSA activity of the extracts on the disk diffusion assay. Ethyl acetate extract of the culture medium nourished with HPE (from fermentative broth) showed a

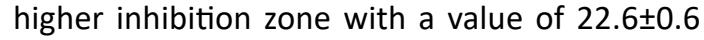
$\mathrm{mm}$. Meanwhile, ethyl acetate extract of culture medium without addition of HPE showed an inhibition zone with a diameter of $8.4 \pm 0.8 \mathrm{~mm}$. The finding revealed the addition of the HPE into the culture medium significantly increased the anti-MRSA activity of endophytic fungus, $L$. pseudotheobromae. This phenomenon might because of the role of certain host's compounds as precursors for the certain secondary metabolite's synthesis by fungal endophytes ${ }^{22}$. Besides, the endophytic fungi produce certain antimicrobial metabolites due to mutualistic interaction with their host, whereby they will utilize some of the host's nutrients ${ }^{34}$. Over the long period of evolution, the mutual relationship between endophytic fungi and their host plants could exploit certain effects on the formulation of the bioactive substances that can benefits humans ${ }^{35}$. However, none of the ethyl acetate extracts prepared from the fungal biomass demonstrated anti-MRSA activity for both culture media. The finding was in parallel with Ibrahim et $\mathrm{al}^{36}$ who studied the anti-fungal activity of an endophytic fungus, Aspergillus flavus in which no activity demonstrated by an extract from fungal biomass. The present study suggested that the secondary metabolites by Lasiodiplodia pseudotheobromae IBRL OS-64 were secreted extracellularly into the fermentative broth. However, the anti-MRSA activity for both fungal extracts were significantly

Table 1. Anti-MRSA activity of fungal extracts on disc diffusion assay

\begin{tabular}{|c|c|c|c|c|c|}
\hline \multirow[t]{3}{*}{ Test bacterium } & \multicolumn{5}{|c|}{ Diameter of inhibition zone $(\mathrm{mm} \pm \mathrm{SD})$} \\
\hline & \multicolumn{2}{|c|}{ Fungal biomass } & \multicolumn{2}{|c|}{ Fermentative broth } & \multirow{2}{*}{$\begin{array}{c}\text { Control } \\
\text { Chloramphenicol }\end{array}$} \\
\hline & YES & $\mathrm{YES}+\mathrm{HPE}$ & YES & $\mathrm{YES}+\mathrm{HPE}$ & \\
\hline MRSA & - & - & $8.4 \pm 0.8^{a}$ & $22.6 \pm 0.6^{b}$ & $29.8 \pm 1.0^{c}$ \\
\hline
\end{tabular}

Notes: YES: yeast extract sucrose broth, HPE: host plant extract, different superscript shows the mean of each dataset was significantly different. 
Table 2. Minimal inhibition concentration (MIC) and Minimal bactericidal concentration $(\mathrm{MBC})$ values of the extracts against MRSA ATCC33591

\begin{tabular}{lccc}
\hline $\begin{array}{l}\text { Culture } \\
\text { media }\end{array}$ & $\begin{array}{c}\mathrm{MIC} \\
(\mu \mathrm{g} / \mathrm{mL})\end{array}$ & $\begin{array}{c}\mathrm{MBC} \\
(\mu \mathrm{g} / \mathrm{mL})\end{array}$ & Ratio \\
\hline YES & 1000 & 8000 & 8 \\
YES + HPE & 250 & 500 & 2 \\
\hline
\end{tabular}

Notes: YES: yeast extract sucrose broth, HPE: host plant extract

lower than the control, chloramphenicol. This phenomenon might be due to the purity of the bioactive compounds in which the fungal crude extracts consist of mixture compounds compared to pure compounds in standard antimicrobial drugs $s^{37}$.

Microdilution broth assay was performed to access the efficiency of the fungal extracts against MRSA. Table 2 shows the MIC and MBC values of the extracts against MRSA. For culture medium supplemented with HPE, the values of MIC and $\mathrm{MBC}$ of the fungal extract were 250 and $500 \mu \mathrm{g} / \mathrm{mL}$, respectively. The fungal extract showed a bactericidal activity against MRSA since the $M B C$ value was only 2 -fold higher than its MIC. According to Krishnan et $\mathrm{al}^{38}$, antimicrobial substances are considered as bactericidal agents if the ratio $\mathrm{MBC} / \mathrm{MIC}$ was less or equal to 4 . On the other hand, the MIC value of the fungal extract prepared from the culture medium without HPE was $1000 \mu \mathrm{g} / \mathrm{mL}$ whilst, its $\mathrm{MBC}$ was $8000 \mu \mathrm{g} / \mathrm{mL}$. The finding indicated that the ratio of $\mathrm{MBC} / \mathrm{MIC}$ of the fungal extract was 8-fold, which considered as a bacteriostatic agent. Hossan et a $^{39}$ reported that antimicrobial extracts are categorized as a bacteriostatic when the ratio $\mathrm{MBC} / \mathrm{MIC}$ was higher than 4 . For both culture media, MIC was significantly lower than $M B C$ values showing that the fungal extract concentration needs to be significantly higher to kill and eliminate the MRSA cells rather than inhibiting them. This finding also suggested that the broth microdilution assay is useful tool to evaluate the efficiency and susceptibility of test bacteria towards the fungal extract. Therefore, the present study provides strong manifest that the culture medium incorporated with HPE is significantly increased the anti-MRSA activity of Lasiodiplodia pseudotheobromae.

Time-kill assays were frequently performed by researchers to study the pharmacodynamics of the antibiotics since this method providing information regarding the killing



- - Chloramphenicol - - YES broth + HPE - - Y YES broth $\quad$ Control

Fig. 1. Time-kill curve of chloramphenicol and various extracts against MRSA ATCC33591. Notes: YES: yeast extract sucrose, HPE: host plant extract. 
Jalil et al. | J Pure Appl Microbiol | 15(3):1398-1408 | September 2021 | https://doi.org/10.22207/JPAM.15.3.32

Table 3. The time to achieve $50,90,99$, and $99.9 \%$ growth reduction in initials inoculum of MRSA ATCC33591

\begin{tabular}{lcccc}
\hline Percentage of & \multicolumn{4}{c}{ Time (hour) } \\
\cline { 2 - 5 } reduction (\%) & Control & YES broth & $\begin{array}{c}\text { YES broth }+ \\
\text { HPE }\end{array}$ & Chloramphenicol \\
\hline 50 & & \multicolumn{4}{c}{$4-8$} & $0-4$ \\
90 & NR & $16-20$ & $4-8$ \\
99 & NR & $20-24$ & $16-20$ & $4-8$ \\
99.9 & NR & NR & $24-28$ & $16-20$ \\
& NR & NR & $32-36$ & $20-24$ \\
\hline
\end{tabular}

Key: $N R=$ not reached

rate of different concentrations of the antibiotics either time-dependent or dose-dependent bactericidal activities ${ }^{40}$. The present study employed this assay since Tam et $\mathrm{al}^{41}$ reported that the time-kill curves are ordinary used by researchers to investigate and determine new antimicrobial agents since the method are ecofriendly and easy to handle. Fig. 1 demonstrates the time-kill curve of chloramphenicol and fungal extracts against the growth of MRSA. In general, the control showed the typical bacterial growth curve with slow growth at the lag phase and the rapid growth of the bacterial cells was observed at the exponential phase. MRSA growth maintains at a stationary phase and then the viable cell counts of bacterial cells were slightly dropped thereafter which is at the death phase. For YES broth extract, the viable cell counts for MRSA was slightly decreased after 4 hours of cultivation period and the bacterial growth was constantly decline until 24 hours of the cultivation time with number of bacterial cell of $3.4 \times 10^{4} \mathrm{CFU} / \mathrm{mL}$. Then, the bacterial growth was observed to be increased thereafter and afterward reached viable cell counts almost mirroring the control. The emergence of resistance cells indicated the YES broth extract was not showed a bactericidal activity on MRSA even at the MIC level of extract concentration since the cell reduction was less than $3 \log 10 \mathrm{CFU} / \mathrm{mL}$. This phenomenon may be due to the emergence of the persistent cell since $\mathrm{Li}$ et $\mathrm{al}^{42}$ reported that persistence happens in a subpopulation of bacterial cells that are not killed by the antibiotic and thus, the heterogeneous response is repeated when they are exposed to the same antibiotic. In the meantime, the bacteria have slower growth rate than most of the population or known as timedependent persistence. Therefore, the mechanism of time-dependent persistence associated with the growth tolerance could slow down the killing process by the antibiotic. Besides, the formation of biofilm also facilitated the emergence of resistant cells that leads to bacterial regrowth. Dakheel et al $^{43}$ reported that MRSA strains able to develop biofilm by releasing extracellular DNA (eDNA) as its important part of biofilm structure and the eDNA could enhance the biofilm stability as well as its resistance to antibiotics. According to Sharma et $\mathrm{al}^{44}$, biofilm is a complex structure containing different bacterial colonies embedded in extracellular polymeric substances (EPS) composed of polysaccharides, protein, and eDNA that showed high resistance to antimicrobial agents. On the other hand, a stagnant growth of the bacterial cells was observed after treated with the extract prepared from YES broth nourished with HPE at the MIC level. However, the growth of MRSA was drastically reduced after $24 \mathrm{~h}$ of the cultivation time with the bacterial cell numbers of $2.8 \times 10^{4} \mathrm{CFU} / \mathrm{mL}$. A declining throughout the incubation period was observed thereafter until it reached 44 hours where almost all the bacterial cells were killed. This finding revealed that the ethyl acetate extract of the endophytic fungal isolate prepared from YES broth supplemented with HPE has strong bactericidal activity towards MRSA. Following that, with the addition of

Table 4. Number of spots on TLC plate for different extracts

\begin{tabular}{lccc}
\hline \multirow{2}{*}{ Extracts } & \multicolumn{3}{c}{ Number of spots } \\
\cline { 2 - 4 } & $\begin{array}{c}\text { Visible } \\
\text { light }\end{array}$ & $\begin{array}{c}\text { Long } \\
\text { wave }\end{array}$ & $\begin{array}{c}\text { Short } \\
\text { wave }\end{array}$ \\
\hline YES broth & 0 & 4 & 5 \\
YES broth + HPE & 1 & 7 & 9 \\
\hline & \multicolumn{3}{c}{ www.microbiologyjournal.org }
\end{tabular}


Table 5. Anti-MRSA activity of different spots on TLC observed under short wave UV light

\begin{tabular}{|c|c|c|c|c|c|}
\hline \multirow[b]{2}{*}{ Spots } & \multicolumn{2}{|c|}{ YES + HPE extract } & \multirow[b]{2}{*}{ Spots } & \multicolumn{2}{|c|}{ YES extract } \\
\hline & $R_{f}$ value & $\begin{array}{l}\text { Diameter of inhibition } \\
\text { zone }(\mathrm{mm} \pm \mathrm{SD})\end{array}$ & & $R_{f}$ value & $\begin{array}{l}\text { Diameter of inhibition } \\
\text { zone }(\mathrm{mm} \pm \mathrm{SD})\end{array}$ \\
\hline 1 & 0.0706 & - & 1 & 0.0652 & - \\
\hline 2 & 0.1882 & - & 2 & 0.2990 & $9.8 \pm 1.2$ \\
\hline 3 & 0.2941 & $8.2 \pm 0.6$ & 3 & 0.4198 & - \\
\hline 4 & 0.3529 & - & 4 & 0.5212 & - \\
\hline 5 & 0.4235 & - & 5 & 0.6499 & - \\
\hline 6 & 0.5294 & - & & & - \\
\hline 7 & 0.5882 & $19.6 \pm 0.9$ & & & - \\
\hline 8 & 0.6471 & - & & & - \\
\hline 9 & 0.7056 & - & & & - \\
\hline
\end{tabular}

standard drug chloramphenicol, the viable cell counts was gradually reduced from the 0 to $16^{\text {th }}$ hour of cultivation time. The bacterial growth graph exhibited a steep decrease in number of bacterial cells thereafter and all the MRSA cells were eliminated after 28 hours of treatment without regrowth of bacteria cell observed. The present study revealed the time-kill study is useful for assessing bactericidal effect of the extract by providing dynamic information between test bacteria and drug.

Table 4 shows the number of spots on TLC plate for both extracts. The TLC results demonstrated a highest number of spots were obtained from ethyl acetate crude extract prepared from YES culture medium containing the HPE. The results revealed that one spot can be observed under a visible light, seven spots under UV lightlong wave $(200 \mathrm{~nm})$, and nine spots under UV lightshort wave $(300 \mathrm{~mm})$. On the other hand, only four spots under UV light-long wave $(200 \mathrm{~nm})$ and five spots under UV light-short wave $(300 \mathrm{~mm})$ were observed on TLC plate of fungal extract prepared from YES broth. The findings revealed the number of spots was higher in the extract prepared from culture medium incorporating the HPE compared to YES broth alone. This discovery revealed that the culture medium with the presence of host plant could significantly improve the production of secondary metabolites by L. pseudotheobromae. The present finding agreed with Salehi et $\mathrm{al}^{45}$ who revealed the culture medium nourished with Corylus avellana extract could enhanced paclitaxel production of Epicoccum nigrum YEF2 and its growth too. The present results confirm the previous study conducted by Taufiq and Darah ${ }^{46}$. Bioautography is a useful common procedure for the detection and separation of the active antimicrobial agents in a mixture of compounds and this assay is popular amongst researchers as its flexibility, easy to conduct, low cost and high throughput ${ }^{47}$. Bioautographic methods combine in situ determination of microbial growth and chromatographic separation. To screen antimicrobial substances on the TLC plate, three different approaches have been introduced such as immersion, direct and contact bioautography ${ }^{48}$. In a contact bioautography, antimicrobial substances on the TLC were placed on the fresh agar that are previously seeded with test microorganisms and this method sometimes not working due to insoluble samples and different diffusion rate from the chromatogram to the agar ${ }^{28}$. On the other hand, the direct bioautography was performed by spaying with or immersing into suspensions of test microorganism that previously growing in the suitable broth and this technique required a lot of attention during manipulation with test microorganisms ${ }^{49}$. The immersion or also known as agar overlay assay was frequently used by researchers whereby the chromatogram is covered with a molten-seeded agar and this procedure is a combination of the direct and contact bioautography ${ }^{48}$. Table 5 demonstrates anti-MRSA activity of different spots on the TLC plate observed under short wave UV light for both extracts. The results revealed that two out of nine spots observed on the TLC plate spotted with YES 


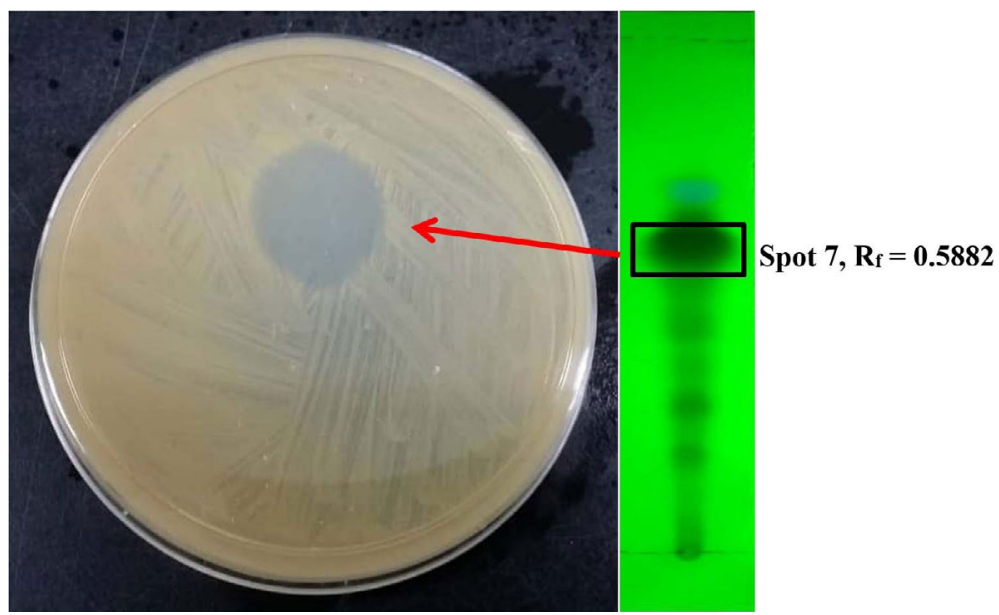

Fig. 2. Anti-MRSA activity of spot 7 of crude extract prepared from YES culture containing host plant extract on TLC plate.

+ HPE extract exerted antibacterial effect towards the test bacterium. Both spots with $R_{f}$ values of 0.2941 (Spot 3) and 0.5882 (Spot 7) exhibited antiMRSA activity with the diameter of inhibition zone of $8.2 \pm 0.6$ and $19.6 \pm 0.9 \mathrm{~mm}$, respectively. Fig. 2 shows the effect of the ethyl acetate extract (that previously prepared from YES culture nourished with HPE ) on spot 7 against MRSA on agar diffusion bioautography assay. On the other hand, for the extract prepared from the YES culture, only one out of five spots showed antibacterial activity against MRSA with the diameter of inhibition zone of $9.8 \pm 1.2 \mathrm{~mm}$. Besides that, spot 3 from YES + HPE extract and spot 2 from YES extract probably the same compound since they shared almost the same $R_{f}$ value with mild antibacterial activity. The findings revealed that the partially purified YES + HPE extract had greater antiMRSA activity compared to partially purified YES extract and this might be due to the synergistic or combined effect of two spots. However, the activity of partially purified extract was slightly decreased compared to the crude extract on disk diffusion assay. According to Soltanian et al ${ }^{50}$, the crude extract was more efficient compared to its fraction due to a synergistic effect by a combination of mycochemical constituents. Besides that, the efficacy of natural drugs is influenced by the synergistic effects of several phytochemical substances rather than a single compound $^{51}$. Moreover, Ginsburg and Deharo et $\mathrm{al}^{52}$ stated that the additive effect happened by the combination of different bioactive compounds and interaction among these substances in a mixture exhibit similar effect to a single compound whereas synergistic effect occurred when the combination of several bioactive substances could demonstrate greater effect than a single compound. Furthermore, the mild anti-MRSA activity of YES extract might be contributed by only spot 2 . The antibacterial activity of the partially purified extract was slightly increase compared to the result of crude fungal extract observed on the disk diffusion assay and this might be due to purity of active compound. Thus, the present finding revealed that the fractionation of the crude extract can improve its antibacterial activity against test bacteria. On the other hand, the finding revealed that the culture medium nourished with host plant extract could induce the formulation of the other bioactive substances by fungal endophytes with antimicrobial activity. The result agreed with the previous study that reported that the endophytic fungal isolate, Phomopsis sp. ED2 was produced only secondary metabolite with anti-candidal activity when inoculated in the culture medium incorporating with host plant extract $^{53}$. This phenomenon demonstrates that fungal endophytes utilizing the nutrients or certain substances provided by their host plant to formulate several compounds that may benefit both. 
The TLC plate was subjected to UV light for photochemical analysis of spots with anti-MRSA activity. For partially purified extract from YES broth, the black spot (under UV light) at $\mathrm{R}_{\mathrm{f}}$ value of 0.2990 was subjected to ferric chloride $\left(\mathrm{FeCl}_{3}\right)$ test. A blue color appears on the TLC plate indicated the presence of phenol. Similar observation also recorded for partially purified extract from YES broth supplemented with HPE at $R_{f}$ value 0.2941 . Both spots may the same compounds since they shared almost similar $R_{f}$ values. Many previous studies reported the capability of phenol as antibacterial agents. For instance, Mace et a ${ }^{54}$ reported two phenolic compounds demonstrated a significant inhibitory activity against three different strains of Streptococcus pyogenes with $\mathrm{MIC}$ and $\mathrm{MBC}$ values in between 0.39 to $6.25 \mu \mathrm{g} /$ $\mathrm{mL}$ and 100 to $>100 \mu \mathrm{g} / \mathrm{mL}$, respectively. Besides, Alves et $a^{155}$ stated that 2,4-dihydroxybenzoic and p-coumaric acids, the phenolic compounds exhibited anti-MRSA activity with MIC values between $0.5 \mathrm{mg} / \mathrm{mL}$ to $1.0 \mathrm{mg} / \mathrm{mL}$. On the other hand, the developed TLC plate of YES + HPE extract with dark spot $\left(R_{f}\right.$ value of 0.5882$)$ was fumigated with iodine crystals vapor in a closed container and a brown spot was observed indicates the presence of lactone. Previous studies reported the potent of lactone as antibacterial agents. Koyama et a ${ }^{56}$ reported the new lactone compound, albocycline isolated from Streptomyces sp. (fermentative broth), exhibited inhibitory effect towards MRSA. They also revealed that the compound able to inhibit biosynthesis of the cell wall's peptidoglycan of Staphylococcus aureus. Besides, Choudhary et $\mathrm{al}^{57}$ reported that the newly identified lactone compound demonstrated significant antifungal and antibacterial activities against test fungus and bacterium Pyricularia oryzae and Bacillus subtilis, respectively. Meanwhile, Fluctuanin showed the highest inhibitory effect towards Bacillus subtilis compared to other sesquiterpene lactones.

\section{CONCLUSION}

The present study shows that an endophytic fungus isolated from medicinal herb, Ocimum sanctum has antibacterial especially anti-MRSA properties. The study revealed that by incorporating the culture medium with host plant extract, the inhibitory effect against MRSA could be enhanced. The discovery is a crucial milestone for further studies regarding mutualistic relationship between fungal endophytes and their hosts as well as their potency in the formulation of bioactive compounds with pharmaceutical properties.

\section{ACKNOWLEDGMENT}

The authors are grateful to Universiti Sains Malaysia for awarding the RUI research grant scheme to support this study.

\section{CONFLICT OF INTEREST}

The authors declare that there is no conflict of interest.

\section{AUTHORS' CONTRIBUTION}

MTMJ did all the experiments and NAZ analyzed the data. DI was the principal investigator, and she supervised the whole works. All the works were performed in her laboratory. She, along with MTMJ and NAZ prepared and corrected the manuscript.

\section{FUNDING}

This project was funded by Universiti Sains Malaysia through the RUI research grant scheme (ac: 1001/PBIOLOGI/811326).

\section{DATA AVAILABILITY}

All datasets generated or analyzed during this study are included in the manuscript.

\section{ETHICS STATEMENT}

This article does not contain any studies with human participants or animals performed by any of the authors.

\section{REFERENCES}

1. Hassoun A, Linden PK, Friedman B. Incidence, prevalence, and management of MRSA bacteremia across patient populations-a review of recent developments in MRSA management and treatment. Crit Care. 2017;21:211. doi: 10.1186/s13054-0171801-3

2. Gary EY, Gebreab YB, Achila OO, et al. MethicillinResistant Staphylococcus aureus (MRSA): Prevalence and Antimicrobial Sensitivity Pattern among Patients-A Multicenter Study in Asmara, Eritrea. Can J Infect Dis Med Microbiol. 2019;2019:8321834. doi: 10.1155/2019/8321834

3. Mikkaichi T, Yeaman MR, Hoffman A. Identifying determinants of persistent MRSA bacteremia using mathematical modeling. PLoS Comput Biol. 2019;15(7):e1007087. doi: 10.1371/journal. 


\section{pcbi.1007087}

4. Guo Z, Hua R, Bai Y, et al. Screening and evaluation of antiphylopathogenic activity of endophytic fungi from live foliages of Ginkgo biloba L. Afr J Microbiol Res. 2011;5:1686-1690. doi: 10.5897/AJMR11.381

5. Bacon CW, White JF. Microbial endophytes. Marcel Deker Inc., New York. 2000:341-388. doi: $10.1201 / 9781482277302$

6. Strobel G, Daisy B. Bioprospecting for microbial endophytes and their natural products. Microbiol Mol Biol Rev. 2003;67(4):491-502. doi: 10.1128/ MMBR.67.4.491-502.2003

7. Zhang HW, Song YC, Tan RX. Biology and chemistry of endophytes. Nat Prod Rep. 2006;23(5):753-771. doi: $10.1039 / \mathrm{b} 609472 \mathrm{~b}$

8. Stierle A, Strobel G, Stierle D. Taxol and taxane production by Taxomyces andreanae, an endophytic fungus of pacific yew. Science. 1993;260:214-216. doi: 10.1126/science.8097061

9. Hussain $\mathrm{H}$, Kock I, Al-Harrasi A, et al. Antimicrobial chemical constituents from endophytic fungus Phoma sp. Asian Pac J Trop Med. 2014;7(9):699-702. doi: 10.1016/S1995-7645(14)60119-X

10. Yan JY, Xie Y, Zhang W, et al. Species of Botryosphaeriaceae involved in grapevine dieback in China. Fungal Divers. 2013;61:221-236. doi: 10.1007/ s13225-013-0251-8

11. Castro-Medina F, Mohali SR, Urbez-Torres JR, Gubler WD. First report of Lasiodiplodia pseudotheobromae causing trunk cankers in Acacia mangium in Venezuela. Plant Dis. 2014;98(5):686. doi: 10.1094/PDIS-02-130160-PDN

12. Dissanayake AJ, Zhang W, Mei L, et al. Lasiodiplodia pseudotheobromae causes pedicel and peduncle discolouration of grapes in China. Australasian Plant Dis. Notes. 2015;10:21. doi: 10.1007/s13314-0150170-5

13. Munirah MS, Azmi AR, Yong SYC, Nur Ain Izzati MZ. Characterization of Lasiodiplodia theobromae and $\mathrm{L}$. pseudotheobromae causing fruit rot on pre-harvest mango in Malaysia. Plant Pathol Quar. 2017;7(2):202213. doi: $10.5943 / p p q / 7 / 2 / 14$

14. Kwon J-H, Choi O, Kang B, et al. Identification of Lasiodiplodia pseudotheobromae causing mango dieback in Korea. Can J Plant Pathol. 2017;39(2):241245. doi: 10.1080/07060661.2017.1329231

15. Meshram V, Saxena S. Erratum to: Potential fibrinolytic activity of an endophytic Lasiodiplodia pseudotheobromae species. Biotechnol. 2016;6:134. doi: 10.1007/s13205-016-0451-5

16. Lu X, Chen G, Li Z, et al. Palmarumycins from the endophytic fungus Lasiodiplodia pseudotheobromae XSZ-3. Helvet Chem Acta. 2014;97:1289-1294. doi: 10.1002/hlca.201300436

17. Taufiq MMJ, Darah I. Anti-MRSA of the ethyl acetate crude extract from Lasiodiplodia pseudotheobromae IBRL OS-64, an endophytic fungus isolated from leaf of Ocimum sanctum Linn. Int J Pharm Pharm Sci. 2018;10 (8):50-55. doi: 10.22159/ijpps.2018v10i8.26527

18. Ho WH, To PC, Hyde KD. Induction of antibiotic production of freshwater fungi using mix-culture fermentation. Fungal Divers. 2003;12:45-51.
19. Dutta D, Puzari KC, Gogoi R, Dutta P. Endophytes: Exploitation as a tool in plant protection. Braz Arch Biol Technol. 2014;57(5):621-629. doi: 10.1590/S15168913201402043

20. Nair DN, Padmavathy S. Impact of endophytic microorganisms on plants, environment and humans. Sci World J. 2014;2014:250693. doi: 10.1155/2014/250693

21. White JFJr, Glenn AE. A study on two fungal epibionts of grasses: Structural features, host relationship and classification in the genus Myriogenospora (Clavicipitales). Am J Bot. 1994;81(2):216-223. doi: 10.1002/j.1537-2197.1994.tb15432.x

22. Tong WY, Darah I, Latiffah Z. Antimicrobial activities of endophytic fungal isolates from medicinal herb Orthosiphon stamineus Benth. J Med Plants Res. 2011;5:831-836.

23. Gogoi DK, Boruah HPD, Saikia R, Bora TC. Optimization of process parameters for improved production of bioactive metabolite by a novel endophytic fungus Fusarium sp. DF2 isolated from Taxus wallichiana of North East India. World J Microbiol Biotechnol. 2008;24(1):79-87. doi: 10.1007/s11274-007-9442-3

24. Taufiq MMJ, Darah I. Antibacterial activity of an endophytic fungus Lasiodiplodia pseudotheobromae IBRL OS-64 residing in leaves of a medicinal herb, Ocimum sanctum Linn. J App Biol Biotech. 2019a;7(02):35-41. doi: 10.7324/JABB.2019.70207

25. Clinical Laboratory and Standard Institute. Performance Standards for Antimicrobial Disk Susceptibility Tests. CLSI Approved Standard Document M2-A9. Wayne, Pennsylvania: CLSI. 2006.

26. Clinical Laboratory and Standard Institute. Methods for Determining Bactericidal Activity of Antimicrobial Agents. CLSI Approved Standard Document M26-A.: Wayne, Pennsylvania: CLSI. 1999.

27. Kagan IA, Flythe MD. Thin-layer chromatographic (TLC) separations and bioassays of plant extracts to identify antimicrobial compounds. J Vis Exp. 2014;85:51411. doi: $10.3791 / 51411$

28. Dewanjee S, Gangopadhyay M, Bhattabharya N, Khanra, Dua TK. Bioautography and its scope in the field of natural product chemistry. J Pharm Anal. 2015;5(2):75-84. doi: 10.1016/j.jpha.2014.06.002

29. Harborne JB. Phytochemical Methods: A Guide to Modern Techniques of Plant Analysis, Chapman \& Hall Ltd., London, UK. 1973a:33-88.

30. Harborne JB. Phytochemical Methods: A Guide to Modern Techniques of Plant Analysis, Chapman \& Hall Ltd., London, UK. 1973b:182-190

31. Hombach M, Zbinden R, Bottger EC. Standardization of disk diffusion results for antibiotic susceptibility testing using the sirscan automated zone reader. BMC Microbiol. 2013;13:225. doi: 10.1186/14712180-13- 225

32. Coorevits L, Boelens J, Claeys G. Direct susceptibility testing by disk diffusion on clinical samples: a rapid and accurate tool for antibiotic stewardship. Eur $J$ Clin Microbiol Infect Dis. 2015;34(6):1207-1212. doi: 10.1007/s10096-015-2349-2

33. Taufiq MMJ, Darah I. Effect of ethyl acetate crude extract of Lasiodiplodia pseudotheobromae IBRL 
OS-64 against oral cavity bacteria with emphasis on Streptococcus mutans. J Appl Pharm Sci. 2019b;9(11):78-85. doi: 10.7324/JAPS.2019.91110

34. Yenn TW, Lee CC, Ibrahim D, Zakaria L. Enhancement of Anti-candidal Activity of Endophytic Fungus Phomopsis sp. ED2, Isolated from Orthosiphon stamineus Benth, by Incorporation of Host Plant Extract in Culture Medium. J Microbiol. 2012;50(4):581-585. doi: 10.1007/s12275-012-2083-8

35. Jia $M$, Chen $L$, Xin $H-L$, et al. A friendly relationship between endophytic fungi and medicinal plants: A systematic review. Front Microbiol. 2016;7:906. doi: 10.3389/fmicb.2016.00906

36. Ibrahim D, Nurhaida, Hong LS. Anti-candidal activity of Aspergillus flavus IBRL-C8, an endophytic fungus isolated from Cassia siamea Lamk leaf. J App Pharm Sci. 2018;8(2):83-87. doi: 10.7324/JAPS.2018.8213

37. Gatsing D, Nkeugouapi CFN, Nkah BFN, Kuiate JR, Tchouanguep FM. Antibacterial activity, bioavailability and acute toxicity evaluation of the leaf extract of Alchornea cordifolia (Euphorbiaceae). Int J Pharmacol. 2010;6(3):173-182. doi: 10.3923/ijp.2010.173.182

38. Krishnan N, Ramanathan S, Sasidharan S, Murugaiyah V, Mansor SM. Antimicrobial Activity Evaluation of Cassia spectabilis Leaf Extracts. Int J Pharmacol. 2010;6(4):510-514. doi: 10.3923/ijp.2010.510.514

39. Hossan MS, Jindal $\mathrm{H}$, Maisha $\mathrm{S}$, et al. Antibacterial effects of 18 medicinal plants used by the Khyang tribe in Bangladesh. Pharm Biol. 2018;56(1):201-208. doi: 10.1080/13880209.2018.1446030

40. Ferro $B E$, van-Ingen J, Wattenberg $M$, van-Soolingen D, Mouton JW. Time-kill kinetics of antibiotics active against rapidly growing mycobacteria. J Antimicrob Chemother. 2015;70(3):811-817. doi: 10.1093/jac/ dku431

41. Tam VH, Schilling AN, Nikolaou M. Modelling timekill studies to discern the pharmacodynamics of meropenem. J Antimicrob Chemother. 2005;55(5):699706. doi: $10.1093 / \mathrm{jac} / \mathrm{dki086}$

42. Li J, Xie S, Ahmed S, et al. Antimicrobial activity and resistance: Influencing factors. Front Pharmacol. 2017;8:364. doi: 10.3389/fphar.2017.00364

43. Dakheel KH, Rahim RA, Neela VK, Al-Obaidi JR, Hun TG, Yusoff K. Methicillin-Resistant Staphylococcus aureus Biofilms and their influence on bacterial adhesion and cohesion. Hind BioMed Res Int. 2016;2016:4708425. doi: $10.1155 / 2016 / 4708425$

44. Sharma D, Misba L, Khan AU. Antibiotics versus biofilm: an emerging battleground in microbial communities. Antimicrob Resist Infect Control. 2019;8:76. doi: 10.1186/s13756-019-0533-3

45. Salehi M, Moieni A, Safaie N. Elicitors derived from Hazel (Corylus avellana L.) cell suspension culture enhance growth and paclitaxel production of Epicoccum nigrum. Sci Rep. 2018;8:12053. doi: 10.1038/s41598-018-29762-3
46. Taufiq MMJ, Darah I. Effects of cultural conditions in enhancing the production of anti-MRSA activity of Lasiodiplodia pseudotheobromae IBRL OS-64, an endophytic fungus isolated from leaf of Ocimum sanctum L. in submerged fermentation system. J Pure Appl Microbiol. 2019;13(4):2517-2531. doi: 10.22207/JPAM.13.4.67

47. Belaqziz M, Tan SP, El-Abbassi A, et al. Assessment of the antioxidant and antibacterial activities of different olive processing wastewaters. PLOS One. 2017;12(9):e0182622. doi: 10.1371/journal. pone. 0182622

48. Paradowska K, Lutek J, Ginalska G. A rapid detection for the inhibition of phosphoglucose isomerase from Escherichia coli by mercury (II) chloride based on TLCautographic analysis - preliminary studies. Curr Issues Pharm Med Sci. 2014;27(2):127-130. doi: 10.2478/ cipms-2014-0030

49. Marston A. Thin-layer chromatography with biological detection in phytochemistry. J Chromatogr $A$. 2011;1218(19):2676-2683. doi: 10.1016/j. chroma.2010.12.068

50. Soltanian H, Rezaeian S, Shakeri A, Janpoor J, Pourianfar HR. Antibacterial activity of crude extracts and fractions from Iranian wild-grown and cultivated Agaricus spp. Biomed Res. 2016;27(1):56-59.

51. Martins S, Amorim EIC, Sobrinho TJSP, et al. Antibacterial activity of crude methanolic extract and fractions obtained from Larrea tridentate leaves. Ind Crops Prod. 2013;41:306-311. doi: 10.1016/j. indcrop.2012.04.037

52. Ginsburg H, Deharo E. A call for using natural compounds in the development of new antimalarial treatments - an introduction. Malar J. 2011;10(1):S1. doi: 10.1186/1475-2875-10-S1-S1

53. Yenn TW, Ngim AS, Zakaria L, Ibrahim D, Ring LC. AntiMRSA activity of Penicillium minioluteum ED24. J Chem Pharm Sci. 2015;8(4):646-650.

54. Mace S, Hansen LT, Rupasinghe HPV. Anti-bacterial activity of phenolic compounds against Streptococcus pyogenes. Medicines. 2017;4(2):25. doi: 10.3390/ medicines4020025

55. Alves MJ, Ferreira IC, Froufe HJ, Abreu RM, Martins A, Pintado M. Antimicrobial activity of phenolic compounds identified in wild mushrooms, SAR analysis and docking studies. J Appl Microbiol. 2013;115(2):346-357. doi: 10.1111/jam.12196

56. Koyama N, Yotsumoto M, Onaka H, Tomoda H. New structural scaffold 14-membered macrocyclic lactone ring for selective inhibitors of cell wall peptidoglycan biosynthesis in Staphylococcus aureus. J Antibiotics. 2013;66:303-304. doi:10.1038/ja.2012.122

57. Choudhary S, Mishra PK. A review on pharmacognocy of bioactive sesquiterpene lactones. Int J Pharmacogn Phytochem Res. 2019;11(3):116-121. doi: 10.25258/ phyto.11.3.4 